\title{
Prevalence and Determinants of Food Insecurity in the Southwestern Benin Setting (West Africa)
}

\author{
Moussiliou Noel Paraiso ${ }^{1}$, Charles Sossa Jerome ${ }^{1, *}$, Faïck Bello ${ }^{1}$, Alphonse Kpozéhouen ${ }^{2}$, \\ Victoire Damienne Agueh ${ }^{1}$, Laurent Ouedraogo ${ }^{2}$, Michel Makoutodé ${ }^{3}$

\begin{abstract}
${ }^{1}$ Department of Health Promotion, Regional Institute of Public Health, University of Abomey-Calavi, Benin ${ }^{2}$ Department of Epidemiology and Biostatistics, Regional Institute of Public Health, University of Abomey-Calavi, Benin ${ }^{3}$ Department of Health and Environment Regional Institute of Public Health, University of Abomey-Calavi, Benin
\end{abstract}

Copyright $\bigcirc 2017$ by authors, all rights reserved. Authors agree that this article remains permanently open access under the terms of the Creative Commons Attribution License 4.0 International License.

\begin{abstract}
Food insecurity affects life quality. The purpose of the study was to determine the prevalence and identify socioeconomic determinants of food insecurity in southwestern Benin setting. This cross-sectional study included 510 households selected in the southwestern of Benin using randomly using multistage cluster technique. Data on dietary habits were collected from heads of households using questionnaire. Food insecurity was determined using food insecurity pillars (food availability, access and use) and the score of food consumption based on the diversity and the frequency of food groups consumption. Among the 510 respondents, $47.7 \%$ were women. The prevalence of food insecurity was 31.5\% (CI95\%: 31.3-31.7). Households heads who has secondary school training level had 0.4 (CI95\%: 0.2-0.9) times less risk to experience food insecurity than those which no schooling. Households heads who has low socio economic level were 4.8 (IC95\%: 2.8-7.8) times more at-risk to experience food insecurity than those of medium socio economic level. The prevalence of food insecurity was high in southwestern Benin setting in 2015. Interventions to improve education level and socio economic conditions are needed to prevent food insecurity in households.
\end{abstract}

Keywords Food Insecurity, Determinants, Socioeconomic, Benin

\section{Introduction}

According to the Food and Agriculture Organization (FAO) in 2014, eight hundred five millions persons that is a one-ninth of the world population experienced a situation of serious under feeding and majority of those persons underfed live in developing countries $[1 ; 2]$. According to the projections, the prevalence of under feeding in Sub-Saharan Africa in 2015 will be $23.2 \%$. [3]. Food insecurity threatens life quality [4] and constitutes a principal cause of child malnutrition [5].

In Benin, food insecurity remains a worrying situation even though the number of persons under fed decreased from 1.5 million in 1992 to 1 million in 2014 with $11 \%$ of the households who were affected with food insecurity [2]. Indeed, this prevalence of food insecurity hides important disparities. The report of the global analysis of the vulnerability and food security in Benin in 2014 showed that the departments of Couffo, Mono in southwestern and Atacora in north were mostly concerned with the high level of food insecurity with respectively $29 \%, 28 \%$ and $25 \%$ of the households [6]. The purpose of this survey is to identify the determinants of food insecurity in southwestern Benin area.

\section{Materials and Methods}

\subsection{Setting}

The study was carried out in southwestern Benin in department of Couffo with 745328 inhabitants.

This area is characterized by a subequatorial climate with two hot seasons and two rainy seasons for the second one. The annual rainfall varies from 900 to $1100 \mathrm{~mm} /$ annually. Those characteristics of the climate undergo some modifications because of certain disruptions [7]. Agriculture is the main economic activity and occupies majority of the population. The households grow mainly maize, cassava and beans. The only cash crops are cotton and groundnuts. The average size of the households was 5.9. Some households have a very low level of expenses whose $50 \%$ is reserved to food [7].

\subsection{Study Design and Population}

This was a cross-sectional and analytic study. The study 
population included the heads of households.

\subsection{Sampling}

Size of the sample was estimated considering the prevalence of food insecurity to be $29 \%$ [6], a relative precision of $5 \%$, design effect of 1.5 , and a non-response rate of $10 \%$, the sample-size came to be 510 . The sample was divided into 51 clusters of 10 households.

The households were selected randomly using a cluster survey technique with multiple stages with proportional allocation according to the size of the villages and neighborhoods. The first grade concerns the choice of the villages where the clusters were formed. The second grade concerned the choice of the households.

\subsection{Study Variables}

The dependent variable was the food insecurity of the family. It was determined from the Food Consumption Score (FCS). The food consumption score is a composite indicator calculated to reflect food diversity and the consumption frequency in a family during a week [8]. It is an indicator of the accessible dimension of food security and the quantity of food consumption. A family is in severe food insecurity when its FCS $\leq 35$ and the family is in food security when its FCS $>35$ [9].

The independent variables were concerned:

- The food availability (size of the fields allocated to food production; use of farming inputs; food stocks; family garden; grown products; family size, food source, conservation techniques, transformation techniques; duration of food stock; number of meals per day);

- The food accessibility (socioeconomic level; source of revenue; climate shocks; area of residence; distance between the house and the market; prohibited food; ethnic groups; food consumption). The level of socioeconomic welfare was a composite variable which corresponds to scores related to household amenities (houses, means of transport and information, energy and water source for domestic use). The total score classified in four categories identified four levels of the socioeconomic welfare: very low, low, medium and high [10].

- The use of the food (water source, clean environment, disease);

- The sociodemographic data of the head of the family age, sex, profession, educational background.

\subsection{Data Collection}

Appropriate standard questionnaire approved by the FAO for households' survey during the global analysis of food security and vulnerability was used. The investigators were formed on its filling. Data collection tools (questionnaires) were pre-tested for required adaptations data were collected from the head of the family.

\subsection{Statistical Analysis}

Data were analyzed using STATA 11 software. The analysis was performed using two approaches: descriptive analysis and regression modelling to determine the factors associated with food insecurity. The proportions with $95 \%$ confidence interval were calculated and the means with their standard deviation was estimated. Dependent variables included in the multivariate logistic model, were those previously associated to food insecurity in univariate analysis at significance level of $20 \%$. Variables were adjusted to the model by the backward stepwise method in the multivariate logistic regression, using a significance level of $5 \%$. Statistical analyses were corrected by the complex sample design, using the set of SVY (Stata Survey) commands in STATA software (version 11). Model fit was assessed using goodness-of-fit test specific to survey sample data, and Wald tests, to select the most parsimonious model.

\subsection{Ethical Considerations}

Local authorities and the participants were informed on the objectives of the survey. Informed consent was obtained from the respondents before the beginning of the data collection. This consent states that the participants are not subject to any harm by refusing to take part in the survey or stopping their collaboration during the survey.

\section{Results}

\subsection{Characteristics of Participants}

Among 510 participants, $47.7 \%$ were women. The age of the respondents varied from 30 and 50 years with a weighted median age of 39 years. Participants with no schooling represented $(66.7 \%)$ and $3.6 \%$ had a higher level of education. The main profession was agriculture $(67.9 \%)$ and the predominant ethnical groups were Adjas (95.9\%) while Minas represented (2.4\%).

\subsection{Food Availability in the Households}

The average size of the households was $6.7 \pm 3.5$ and they were mostly $(56.5 \%)$ over $5 \mathrm{~km}$ of the markets. Agriculture was the most frequent occupation (92.9\%) and the main food product was maize and $33.7 \%$ grow also cash crops in addition to food products. They grow (47.9\%) on areas varying between one and two hectares. Food stock was available $(76.3 \%)$, but $70.2 \%$ did not have family garden. Among participants, $20.5 \%$ had no access to crop conservation techniques and $51.8 \%$ had no access to food transformation techniques.

\subsection{Access and Use of Food}

The main source of income of the households was 
agriculture (80.9\%). Among participants, $62.0 \%$ had a low socioeconomic level and $33.6 \%$ had some prohibited food. Rainfall irregularity was found as handicap for $86.3 \%$. Observations showed that $54.5 \%$ of the households lived in an unsafe environment, $43.5 \%$ had run-off water as water source and $53.3 \%$.

\subsection{Food Insecurity in Households}

Among participants investigated, $31.5 \%$ ( $\mathrm{IC}_{95}: 31.3$ - 31.7) experienced food insecurity.

\subsection{Determinants of Food Insecurity in Households in Univariate Analysis}

\subsubsection{Determinants Related to the Head of the Family}

Table 1 shows that the heads of the household with primary school level, secondary and higher had respectively: 0.51 (CI95: $0.3-0.9$ ); 0.2 (CI95: $0.1-0.5$ ) and 0.3 (CI95: $0.1-1.0)$ times less risk of being in food insecurity than those with no education. The heads of household who are civil servants had less risk to be affected by food insecurity than the ones who are farmers 0.3 (CI95\%: 0.1-1.0).

\subsubsection{Determinants Related to Food Availability}

Table 2 shows that the households who practiced agriculture were $3.4 \%$ (CI95\%: 1.36 - 8.55) times more at risk to be affected by food insecurity than those who did not.

When the number of daily meal increased by one unit, the risk of being affected with food insecurity was reduced of 0.7 (CI95\%: $0.5-1.0$ ), whereas the households who did not transform food were 1.6 (CI95\%: 1.1 - 2.4) at-risk to experience food insecurity than those who transform food.

\subsubsection{Determinants Related to Food Access}

Table 3 summarizes the links between the factors related to food access and food insecurity. The households with only one source of income had 1.9 (CI95\%: 1.1 - 3.3) times more risk to experience food insecurity than those who has two or more source of income. Households who lived in rural areas had 2.69 (IC95\%: 1.65 - 4.37) times more risk than those living in urban areas. Living at a distance higher than $5 \mathrm{~km}$ of the market increased 1.17 (CI95\%: $1.13-2.53$ ) times the likelihood of being in food insecurity. Households with low socioeconomic level had 5.6 (CI95\%: 3.4 - 9.23) times risk to be affected with food insecurity than others.

\subsection{Determinants of Food Insecurity in Multivariate Analysis}

Table 4 describes the results of the logistic regression of the dependent variable on the independent variables. The heads of household with secondary education level had low risk 0.4 (CI95\%: $0.2-0.9$ ) to be affected by food insecurity than those with no education level. Households with low socioeconomic level had 4.8 (C95\%: 2.8 - 7.8) times more risk to be affected with food insecurity than those with medium socioeconomic level.

Table 1. Participants characteristics and food insecurity in households, southwestern Benin, $2015(\mathrm{n}=510)$

\begin{tabular}{|c|c|c|c|c|c|}
\hline \multirow{2}{*}{ Variables } & \multicolumn{2}{|c|}{ Food Insecurity } & \multirow{2}{*}{ OR } & \multirow{2}{*}{ C195\% } & \multirow{2}{*}{ p-value } \\
\hline & Yes & No & & & \\
\hline \multicolumn{6}{|l|}{ Age } \\
\hline Under 60 years & 147 & 300 & 1 & & 0.81 \\
\hline 60 years and more & 19 & 44 & 0.9 & $0.5-1.7$ & \\
\hline \multicolumn{6}{|l|}{ Sex } \\
\hline Male & 77 & 190 & 1 & & 0.064 \\
\hline Female & 89 & 154 & 1.4 & $1.0-2.1$ & \\
\hline \multicolumn{6}{|l|}{ Ethnical groups } \\
\hline Adja & 163 & 326 & 1 & & \\
\hline Fon & 2 & 6 & 0.6 & $0.1-3.3$ & 0.6 \\
\hline Yoruba & - & 1 & - & - & - \\
\hline Mina & 1 & 11 & 0.2 & $0.02-1.5$ & 0.13 \\
\hline \multicolumn{6}{|l|}{ Education level } \\
\hline None & 130 & 212 & 1 & & \\
\hline Primary & 26 & 70 & 0.5 & $0.3-0.9$ & 0.013 \\
\hline Secondary & 1 & 47 & 0.2 & $0.1-0.5$ & 0.001 \\
\hline Higher level & 3 & 15 & 0.3 & $0.1-1.0$ & 0.049 \\
\hline \multicolumn{6}{|l|}{ Occupation } \\
\hline Farmer & 131 & 215 & 1 & & \\
\hline Civil servants & 4 & 19 & 0.3 & $0.1-1.0$ & 0.049 \\
\hline Craftsman & 16 & 43 & 0.5 & $0.2-0.9$ & 0.017 \\
\hline Trader & 13 & 51 & 0.4 & $0.2-0.8$ & 0.007 \\
\hline Employee & 2 & 16 & 0.2 & $0.04-0.8$ & 0.023 \\
\hline
\end{tabular}


Prevalence and Determinants of Food Insecurity in the Southwestern Benin Setting (West Africa)

Table 2. Food production and food insecurity in households, southwestern Benin, $2015(\mathrm{n}=510)$

\begin{tabular}{|c|c|c|c|c|c|}
\hline \multirow{2}{*}{ Variables } & \multicolumn{2}{|c|}{ Food insecurity } & \multirow{2}{*}{ OR } & \multirow{2}{*}{ CI95\% } & \multirow{2}{*}{ p-value } \\
\hline & Yes & No & & & \\
\hline \multicolumn{6}{|l|}{ Working in agriculture } \\
\hline No & 3 & 30 & 1 & & \\
\hline Yes & 160 & 314 & 3.4 & $1.4-8.6$ & 0.009 \\
\hline \multicolumn{6}{|l|}{ Types of production } \\
\hline Food & 104 & 207 & 1 & & \\
\hline Cash crops & 2 & 1 & 5.4 & $0.5-6.3$ & 0.175 \\
\hline Both & 51 & 106 & 1.0 & $0.7-1.6$ & 0.86 \\
\hline \multicolumn{6}{|l|}{ Cultivated area } \\
\hline Less than 1 hectare & 51 & 116 & 1 & & \\
\hline $1-2$ hectares & 83 & 148 & 1.3 & $0.8-2.0$ & 0.28 \\
\hline More than 2 hectares & 26 & 50 & 1.30 & $0.7-2.4$ & 0.4 \\
\hline \multicolumn{6}{|l|}{ Use of fertilizers } \\
\hline Yes & 155 & 301 & 1 & & \\
\hline No & 5 & 13 & 0.9 & $0.3-2.9$ & 0.89 \\
\hline \multicolumn{6}{|l|}{ Stock duration (monthly) } \\
\hline $0-4$ & 63 & 106 & 1 & & \\
\hline $5-8$ & 50 & 113 & 0.8 & $0.5-1.3$ & 0.37 \\
\hline $9-12$ & 49 & 108 & 0.9 & $0.6-1.5$ & 0.74 \\
\hline \multicolumn{6}{|l|}{ Garden } \\
\hline Yes & 47 & 110 & 1 & & \\
\hline No & 119 & 234 & 1.3 & $0.8-2.0$ & 0.26 \\
\hline \multicolumn{6}{|l|}{ Size of households } \\
\hline$<=7$ & 119 & 226 & 1 & & \\
\hline $8-15$ & 45 & 108 & 0.8 & $0.5-1.3$ & 0.43 \\
\hline $16-26$ & 2 & 10 & 0.6 & $0.1-2.7$ & 0.45 \\
\hline \multicolumn{6}{|l|}{$\begin{array}{l}\text { Access to technique of } \\
\text { conservation }\end{array}$} \\
\hline Yes & 131 & 274 & 1 & & \\
\hline No & 35 & 70 & 1.0 & $0.6-1.6$ & 0.92 \\
\hline \multicolumn{6}{|l|}{$\begin{array}{l}\text { Access to technique of } \\
\text { transformation }\end{array}$} \\
\hline Yes & 66 & 181 & 1 & & \\
\hline No & 100 & 163 & 1.6 & $1.1-2.4$ & 0.014 \\
\hline \multicolumn{6}{|l|}{ Food stocks } \\
\hline Yes & 130 & 256 & 1 & & \\
\hline No & 36 & 88 & 0.8 & $0.5-1.3$ & 0.43 \\
\hline
\end{tabular}


Table 3. Food access, food use and food insecurity in household, southwestern Benin, $2015(n=510)$.

\begin{tabular}{|c|c|c|c|c|c|}
\hline \multirow{2}{*}{ Variables } & \multicolumn{2}{|c|}{ Food insecurity } & \multirow{2}{*}{ OR } & \multirow{2}{*}{ CI95\% } & \multirow{2}{*}{ p-value } \\
\hline & Yes & No & & & \\
\hline \multicolumn{6}{|c|}{ FACTORS RELATED TO FOOD ACCESS } \\
\hline \multicolumn{6}{|l|}{ Sources of income } \\
\hline 2 and mores & 22 & 77 & 1 & & \\
\hline Less than 2 & 144 & 267 & 1.9 & $1.1-3.3$ & 0.019 \\
\hline \multicolumn{6}{|l|}{ Shock } \\
\hline None & 14 & 55 & 1 & & \\
\hline Dry season & 152 & 289 & 2.7 & 1.45 .2 & 0.003 \\
\hline \multicolumn{6}{|l|}{ Prohibited food } \\
\hline No & 104 & 233 & 1 & & \\
\hline Yes & 62 & 111 & 1.2 & $0.8-1.8$ & 0.32 \\
\hline \multicolumn{6}{|l|}{ Area of residence } \\
\hline Urban & 28 & 118 & 1 & & \\
\hline Rural & 138 & 226 & 2.7 & $1.7-4.4$ & $<0.001$ \\
\hline \multicolumn{6}{|l|}{ Market distance- area } \\
\hline Less than $5 \mathrm{~km}$ & 63 & 159 & 1 & & \\
\hline More than $5 \mathrm{~km}$ & 103 & 185 & 1.7 & $1.1-2.5$ & 0.009 \\
\hline \multicolumn{6}{|l|}{ Level of economic welfare } \\
\hline Medium & 25 & 169 & 1 & & \\
\hline Low & 141 & 175 & 5.6 & $3.4-9.2$ & $<0.001$ \\
\hline \multicolumn{6}{|c|}{ FACTORS RELATED TO FOOD USE } \\
\hline \multicolumn{6}{|l|}{ Health expenses } \\
\hline Less than $50 \%$ of the budget & 78 & 160 & 1 & & \\
\hline $50 \%$ and more of the budget & 88 & 184 & 0.97 & $0.7-1.4$ & 0.89 \\
\hline \multicolumn{6}{|l|}{ Water source } \\
\hline Tap & 12 & 45 & 1 & & \\
\hline Well & 78 & 149 & 1.7 & $0.8-3.4$ & 0.16 \\
\hline Run-off water & 76 & 150 & 1.8 & $0.9-3.7$ & 0.11 \\
\hline \multicolumn{6}{|l|}{ Safety } \\
\hline Yes & 78 & 163 & 1 & & \\
\hline No & 88 & 181 & 0.95 & $0.6-1.4$ & 0.81 \\
\hline
\end{tabular}


Table 4. Determinants of food insecurity in households, multiple logistic regression, initial and final model, southwestern Benin, $2015(\mathrm{n}=510)$.

\begin{tabular}{|c|c|c|c|c|c|}
\hline \multirow[b]{2}{*}{ Variables } & \multirow{2}{*}{$\begin{array}{c}\text { Food } \\
\text { insecurity } \\
\text { (Yes) }\end{array}$} & \multicolumn{2}{|c|}{ Initial model } & \multicolumn{2}{|c|}{ Final model } \\
\hline & & OR (CI95\%) & $\mathrm{p}$-value & OR (CI95\%) & p-value \\
\hline \multicolumn{6}{|l|}{ Education level } \\
\hline None & 130 & 1 & & 1 & \\
\hline Primary & 26 & $0.5(0.1-0.5)$ & 0.013 & $0.8(0.5-1.4)$ & 0.41 \\
\hline Secondary & 1 & $0.2(0.30-0.87)$ & 0.001 & $0.4(0.2-0.9)$ & 0.032 \\
\hline Higher level & 3 & $0.3(0.07-0.99)$ & 0.049 & $0.7(0.2-2.5)$ & 0.54 \\
\hline \multicolumn{6}{|l|}{ Occupation } \\
\hline Farmer & 131 & 1 & & & \\
\hline Civil servants & 4 & $0.3(0.1-0.99)$ & 0.049 & & \\
\hline Craftsman & 16 & $0.5(0.2-0.9)$ & 0.017 & & \\
\hline Trader & 13 & $0.39(0.2-0.8)$ & 0.007 & & \\
\hline Employee & 2 & $0.2(0.04-0.78)$ & 0.023 & & \\
\hline
\end{tabular}

Working in agriculture

$\begin{array}{lccc}\text { No } & 3 & 1 & \\ \text { Yes } & 160 & 3.4(1.4-8.6) & 0.009\end{array}$

Types of production

Food

Cash crops

Two types (Both)

Food transformation

Yes

No

Number of source of

income

2 and mores

Distance with the market

22

66

00

$1.6(1.1-2.4)$

0.014

$5.4(0.47-6.25) \quad 0.175$

$1.03(0.7-1.6) \quad 0.86$

Level of economic welfare
Less than 2

Shock

None

Dry season

Area of residence

Urban

Rural

28

138

Less than $5 \mathrm{~km}$

$5 \mathrm{~km}$ and more

63

103

144

14

152

$$
\begin{gathered}
\text { Medium } \\
\text { Low }
\end{gathered}
$$

25

141

$1.9(1.1-3.3)$

0.019

1

$2.7(1.4-5.2) \quad 0.003$

Drink water source

$\begin{array}{ll}\text { Tap } & 12 \\ \text { Well } & 78 \\ \text {-off water } & 76\end{array}$

$$
2.7(1.6-4.4) \quad 0.000
$$

$\begin{array}{cc}1 & \\ (1.1-2.5) & 0.009\end{array}$




\section{Discussion}

The study examined the socioeconomic determinants of food insecurity of the households, in southwestern Benin. The prevalence of food insecurity in household was $31.5 \%$. Education level and the socioeconomics level were its determinants.

\subsection{Prevalence of Food Insecurity}

The prevalence of food insecurity was a little higher than those reported $(28 \%)$ in the global analysis survey of the vulnerability of food security in 2013 [3]. The difference might be from the fact that in the present study, data were collected in weld period. A similar prevalence was reported in Niger in 2006 [11]. However, a prevalence of food insecurity of $22 \%$ has been observed in Chad in 2013 [12]. This difference might be explained by the fact that the survey was conducted during a post-harvest period and did not concern rural households. Higher prevalence were reported in Democratic Republic of Congo considering the fact that the country faced many political instabilities, numerous conflicts that deprived the population from their cultivation soils and stop them (most of the households) to practice agriculture [13].

\subsection{Determinants of Food Insecurity}

The heads of the household who were educated were less at-risk to be affected by food insecurity than those who were not. The same association was observed in several surveys $[11 ; 12 ; 14-16]$. However, the survey that went on in Ivory Coast by Kinimo (2013) came up with a reverse association. The author observed that the uneducated heads of household were less at risk to be affected by food insecurity than those with the primary level. This was justified by the fact that no schooling households were mainly farmers who practiced auto consumption while the ones with primary level are often unemployed in towns [15].

Contrary to what reported other studies $[17 ; 18]$; the sex of the head of the household was not associated with food insecurity. The fact is that the heads of the households (in the present study) who are women had access to the soil and can then farm and diversifies their food consumption. The age of the heads of the household was not associated to food insecurity. Old heads of household hire the youth to do the farming job on their soils. A similar association was found in study conducted by Owolade and al. in Nigeria and Omidvar and al. in Iran. Meanwhile, other surveys pointed out an obvious fact of an association between the high age of the heads of household and food insecurity $[7 ; 12 ; 19 ; 20]$.

Our results showed a great association between the level of socioeconomic welfare and food insecurity. Indeed, the households with a low socioeconomic welfare level were at high risk to be affected by food insecurity than the households with a medium socioeconomic level. Other surveys showed similar results $[3 ; 12 ; 21]$. The low level of socioeconomic welfare is characterized by the inability to produce sufficient income to ensure adequate food needs. A consequence of the poor state of the household would be food insecurity because the economic access to food is reduced for the poor household due to low income [22; 23].

Contrary to our results concerning the area of the households, Ategbo (1993) found that the living environment was associated to food insecurity. The author reported that households living in rural areas were more at risk to be affected by food insecurity than those living in urban areas [24]. Other studies came out with the same results. $[6 ; 12 ; 25]$. Indeed, households living in the rural areas produce foods and sell part of them. More and more, climate changes reduce the quantity of crops.

The limits of this survey are related to the fact that the SCA captures only a week consumption and does not include season variations and food consumption although it's a valid proxy of food security.

\section{Conclusions}

The prevalence of food insecurity remains high in department of Couffo in Benin in 2015. The education level and the socioeconomic welfare level of the head of household were the socioeconomic determinants of food insecurity. Schooling strategies and interventions that increase incomes of households are needed to prevent households from food insecurity.

\section{Acknowledgements}

We are very grateful to participants in the study.

\section{Author Contributions}

The research proposal was written by MNP CSJ and FB. The data collection was realized by FB. Data analysis was assured by MNP, FB and CSJ. All the authors had contributed to the revision of this paper.

\section{REFERENCES}

[1] FAO, IFAD, WFP. The state of food insecurity in the world 2015. Meeting the 2015 international hunger targets: taking stock of uneven progress. [On line], Food and agriculture organization of the United Nations, Roma, 2015. [cited. 09. 10. 2016]. <http://www.fao.org/3/a-i4646e.pdf>

[2] FAO, IFAD, WFP. The state of food insecurity in the world 214: Strengthening the enabling environment for food security and nutrition. [On line], Food and agriculture organization of the United Nations, Roma, 2014. [cited. 09. 


\section{2016] <http://www.fao.org/3/a-i4030e.pdf>}

[3] Whitaker R.C., Phillips S.M., Orzol SM. Food insecurity and the risks of depression and anxiety in mothers and behavior problems in their preschool-aged children. Pediatrics. 2006; 118: e859-68.

[4] Isanaka S., Mora-Plazas M., Lopez-Arana S., Baylin A., Villamor E. Food insecurity is highly prevalent and predicts underweight but not overweight in adults and school children from Bogotá, Colombia. J Nutr. 2007;137:2747-55

[5] PAM. Analyse Globale de la Vulnérabilité et de la Sécurité Alimentaire. Bénin: PAM; 2014. 146p

[6] AKOMAGNI LA. Monography of comune of Aplahou, Benin. Cotonou; 2006. 41p

[7] World Food Programme. Food consumption analysis Calculation and use of the food consumption score in food security analysis, 2009, Rome, 24p

[8] Programme alimentaire mondial. Enquête sur la Sécurité Alimentaire des Ménages en Mauritanie. 2009, Nouakchott, $86 \mathrm{p}$

[9] Institut national de la statistique et de l'analyse économique. Enquête Démographique et de Santé du Bénin (EDSB-IV) 2011-2012.Contonou, 2013, 402p

[10] PAM, FAO. UNICEF. Enquête conjointe sur la vulnérabilité à l'insécurité alimentaire des ménages au Niger. Niamey, PAM, 2006. $171 \mathrm{p}$

[11] FAO, PAM, Ministère de l'agriculture. Enquête Nationale de la Sécurité Alimentaire des ménages ruraux. Ndjamena, FAO; 2013. 46p

[12] Programme Alimentaire Mondial. République démocratique du Congo. Analyse globale de la sécurité alimentaire et de la vulnérabilité, 2007, Kinshasa, 85p

[13] Chinnakali P,, Upadhyay RP, Shokeen D, Kavita S, Manpreet $\mathrm{K}$, Arvind $\mathrm{K}$ et al. Prevalence of Household-level Food Insecurity and Its Determinants in an Urban Resettlement Colony in North India. J Health Popul Nutr. 2014; 32 (2):227-36.

[14] Yabile K.R., Déterminants de la sous-alimentation des ménages en côte d'ivoire : cas des régions centre et centre-est. Eur Sci J. 2013; 9 (14): 207-28

[15] Chinnakali P., Upadhyay R.P, Shokeen D., Singh K, Kaur M, Singh AK, et al. Prevalence of household-level food insecurity and its determinants in an urban resettlement colony in north India. J health Pop Nutr. 2014; 32(2):227-36.

[16] Omidvar N., Ghazi-Tabatabie M., Sadeghi R., Mohammadi F., Abbasi-Shavazi M.J. J Health Popul Nutr. 2013; 31(3): 356-366.

[17] Taondyande M., mesure de la sous-alimentation: une comparaison de l'Approche paramétrique et non paramétrique. Rome; FAO: 2009.

[18] Nigatsu R., Small holder farmers coping strategies to household food insecurity and hunger in Southern Ethiopia. Ethiopian J Environ Studies Management. 2011; 4(1): 39-48

[19] Janin P.. La vulnérabilité alimentaire des Sahéliens: concepts, échelles et enseignements d'une recherche de terrain. L'Espace géographique. 2006; 35: 355-66.

[20] Van Liere M.J. Coping with household food insecurity: a longitudinal and seasonal study among the Otamary in north-western in Benin [these: Nutr]. Wageningen: University of Wageningen; 1993.

[21] Darmon N, Vieux F, Bocquier A, Lioret S, Dubuisson C, Caillavet F. Insécurité alimentaire pour des raisons financières en France. [On line]. Les publics et leurs conditions de vie 2009-2010. [cited. 09. 10. 2016] $<$ https://www.onpes.gouv.fr/IMG/pdf/Darmon.pdf $>$

[22] Azoulay G, Dillon J.C. La sécurité alimentaire en Afrique: manuel d'analyse et d'élaboration des stratégies. Tiers-Monde, 1994; 35 (139): 709-711

[23] Ategbo E-A.D., Food and nutrition insecurity in northern Bénin: impact of growth performance of children and on year to year nutritional status of adults [thèse: Nutr]. Wageningen: University of Wageningen; 1993.

[24] Koukoui B.JA., Evaluation de l'état nutritionnel des hommes âgés vivant dans la sous-préfecture de Ze [thèse: Agronomie]. Calavi: Université d'Abomey-Calavi; 1993 